\title{
HUBUNGAN ANTARA KEPUASAN KERJA DENGAN PERILAKU KEWARGAORGANISASIAN (PKO) GURU DI SMK NEGERI KECAMATAN PASAR MINGGU KOTA ADMINISTRASI JAKARTA SELATAN (2015)
}

\author{
Dwi Sakti Nugroho, Sutjipto, Matin \\ nugroho.sakti@gmail.com
}

\begin{abstract}
This study aims to know there is a relationship between job satisfaction with teacher OCB at Vocational High School Pasar Minggu, South Jakarta Administration. This research use quantitative with two variables there in, namely: $(X)$ job satisfaction as independent variables and (Y) $O C B$ as the dependent variable. The method used is survey method with the results of the analysis of correlational studies. The population in this study are teacher's at vocational high school in Pasar Minggu, South Jakarta there is 275 teachers. Samples were taken by using simple random sampling technique. The technique is based on the sample size used in this study as many as 73 teachers. Data collection for the variable $(X)$ job satisfaction and variable $(Y)$ OCB using a questionnaire. Hypothesis testing is done using product moment correlation formula in can correlation coefficient $(r)=0,45283$ and based on the results of hypothesis testing using $t$-test obtained t for $4.280>1.994$ t-table. From this research, we get there's positive relation between job satisfaction with $\mathrm{OCB}$ at Vocational High School Pasar Minggu, South Jakarta Administration. The contributions made by teachers job satisfaction on OCB, amounted to $20.51 \%$.
\end{abstract}

Keywords: Job Satisfaction, OCB.

\section{Pendahuluan}

Dalam konteks perilaku keorganisasian, perilaku guru sebagai Pegawai Negeri Sipil berkaitan dengan perilaku penting dari seorang pegawai dalam sebuah organisasi yaitu perilaku ekstra dalam bekerja atau perilaku baik warga organisasi yang popular sebagai perilaku kewargaorganisasian (PKO), yang dalam bahasa inggrisnya disebut Organizational Citizenship Behavior $(O C B)$. Dalam skripsi ini selanjutnya digunakan terminologi perilaku kewargaorganisasian (PKO). Guru yang menampilkan PKO akan melakukan tindakan ekstra melebihi tugas resminya agar efektivitas organisasi dapat meningkat dan berdampak pada peningkatan mutu lembaga pendidikan yang menaunginya. Guru yang memiliki tingkat PKO yang tinggi akan memiliki loyalitas dan pengabdian pada organisasinya. Tetapi faktanya masih banyak permasalahan yang terkait dengan PKO guru.

Berdasarkan informasi yang diperoleh dari hasil grandtour, permasalahan tentang perilaku kewargaorganisasian guru di SMK Negeri Kecamatan Pasar Minggu yaitu mengenai implementasi RPP yang masih kurang dalam kegiatan pembelajaran. Bahwa masih terdapat ketidaksesuaian antara perencanaan RPP dengan pelaksanaannya dalam kegiatan pembelajaran yang dilakukan oleh guru. Contohnya dalam RPP 
dicantumkan bagian-bagian pembelajaran yang harus dilakukan tetapi dalam pelaksanaan pembelajaran tidak semua dilakukan. Selain itu, alokasi waktu yang sudah ditentukan dalam perencanaan RPP tetapi dalam pelaksanaan pembelajarannya tidak sesuai. Hasil temuan permasalahan di atas menguraikan bahwa terdapat gejala pada guru yang menunjukkan PKO guru masih rendah. PKO ini tentunya akan berdampak pada efektivitas organisasi pendidikan.

Munculnya PKO pada guru dapat memberikan dampak positif tidak hanya bagi guru tetapi juga memberikan kontribusi pada satuan pendidikan untuk mecapai tujuan pendidikan. Kinerja guru secara individu akan mempengaruhi kinerja tim atau kelompok dan pada akhirnya mempengaruhi kinerja organisasi secara keseluruhan. Bila sudah seperti itu maka tujuan organisasi akan dapat terwujud secara efektif dan efisien.

PKO yang dimiliki guru merupakan perwujudan dari persepsi guru terhadap pekerjaannya. Untuk dapat meningkatkan PKO guru maka sangat penting bagi organisasi untuk mengetahui apa yang menyebabkan timbulnya atau meningkatnya PKO. Kepuasan kerja dapat dikatakan sebagai faktor yang dominan terhadap PKO guru. Meningkatnya kepuasan kerja yang dirasakan para guru mempengaruhi PKO guru dalam kondisi kerja sehari-hari. Guru yang memiliki kepuasan tampaknya cenderung berbicara secara positif tentang satuan pendidikan, membantu individu lain, dan melewati harapan normal dalam pekerjaan mereka. Hal ini juga dapat menunjukkan bahwa perilaku guru saat berada di sekolah bisa menjadi sumber inspirasi dan motivasi, serta dapat menjadi sosok yang bisa dicontoh bagi peserta didik.

Guru yang merasakan kepuasan dalam bekerja tentunya akan menerapkan PKO untuk berupaya semaksimal mungkin dengan segenap kemampuan yang dimiliki untuk memberikan performa terbaiknya kepada satuan pendidikan tempat ia bekerja. Bahkan, guru yang mempunyai kepuasan kerja akan memiliki loyalitas dan pengabdian pada organisasi dengan kesediaan untuk melakukan hal yang melebihi tanggung jawab formalnya.

Penelitian ini dilakukan untuk mengetahui apakah terdapat hubungan antara kepuasan kerja dengan perilaku kewargaorganisasian (PKO) guru di SMK Negeri Kecamatan Pasar Minggu Kota Administrasi Jakarta Selatan. Adapun judul penelitian ini adalah "Hubungan Antara Kepuasan Kerja dengan Perilaku Kewargaorganisasian (PKO) Guru di SMK Negeri Kecamatan Pasar Minggu Kota Administrasi Jakarta Selatan (2015)".

\section{Kajian Teori}

Schermerhorn, et.al (2010:74) menyatakan, "Organizational citizenship behaviors are the extras people do to go the extra mile in their work". Selanjutnya, Robbins dan Coutler (2007:419) menyatakan, "Organizational Citizenship Behavior is discretionary behaviour that's not part of an employee's formal job requirements, but which promotes the effective functioning of the organization". Luthans (2011:149) menjelaskan, "ocb as individual behavior that is discretionary, not directly or explicitly recognized by the formal reward system, and that in the aggregate promotes the effective functioning of the organization".

George dan Jones (2008:95) menjelaskan "Organizational citizenship behavior (OCB) is behavior that is above and beyond the call of duty-that is, behavior that is not required of organizational members but is nonetheless necessary for organizational survival and 
effectiveness". Hellriegel dan Slocum (2011:186) menyatakan, "Organizational citizenship behaviors are employee behaviors that go above and beyond their job requirements".

Menurut Griffin dan Moorhead (2014:80) menyatakan, "Organizational citizenship refers to the behavior of individuals who make a positive overall contribution to the organization". Kreither dan Kinicki (2008:174) menyatakan, "Organizational citizenship behaviors (OCBs) consist of employee behaviors that are beyond the call of duty".

Jex (2002:105) menyatakan "OCB is essentially a dimension of job performance, if we adopt a broad view of performance. According to Organ (1977, 1994), OCB in organizations can be categorized as five different types: altruism, courtesy, sportsmanship, conscientiousness, civic virtue". Locke (2009:86) menyatakan, "Organizational citizenship behavior (also referred to as contextual performance, extra - role behavior, etc.) includes actions that go beyond task or technical performance. They facilitate the attainment of organizational goals by contributing in a positive way to its social and psychological environment. $O C B$ includes helping, protecting the organization from undeserved harm, making constructive suggestions, and spreading goodwill”.

Dimensi-dimensi PKO juga diungkapkan oleh Luthans (2011:149) yaitu "Motivational dimensions, job satisfaction, and organizational commitment clearly relate to OCBs. Besides being extra-role or going beyond "the call of duty," other major dimensions are that $O C B$ s are discretionary or voluntary in nature and that they are not necessarily recognized by the the formal reward system of the organization". George dan Jones (2008:87) menyatakan "Examples of $O C B$ include helping coworkers; protecting the organization from fire, theft, vandalism, and other misfortunes; making constructive suggestions; developing one's skills and capabilities; and spreading goodwill in the larger community".

Jex (2002:106) menyatakan "Other than affect, fairness, and dispositions, a handful of other factors have been proposed to impact the performance of $O C B$, although none of these has received extensive empirical scrutiny. For example, Chattopadhyay found evidence that $O C B$ is impacted by the demographic composition of work groups. It has also been found that the performance of OCB may be impacted by other factors, such as job-related stressors".

Hendry (2013) mengutip dari beberapa ahli mengkategorikan faktor yang mempengaruhi PKO terdiri dari : 1) Perbedaan individu, meliputi: kepribadian (misalnya kesadaran dan keramahan), kemampuan, pengalaman, pelatihan, pengetahuan, ketidakpedulian dengan penghargaan, dan kebutuhan untuk otonomi, motivasi, kepribadian, kebutuhan dan nilai individu. 2) Sikap kerja, beberapa faktor yang diduga mempengaruhi $O C B$ antara lain : komitmen organisasi, persepsi kepemimpinan dan dukungan organisasi, kepuasan kerja, persepsi keadilan. 3) Faktorfaktor kontekstual adalah pengaruh eksternal yang berasal dari pekerjaan, bekerja kelompok, organisasi, atau lingkungan. Variabel Kontekstual meliputi: karakteristik tugas, sikap pada pekerjaan, gaya kepemimpinan, karakteristik kelompok, budaya organisasi, profesionalisme dan harapan peran sosial.

Hasibuan (2005:202) menyatakan bahwa kepuasan kerja dalam pekerjaan adalah kepuasan kerja yang dinikmati dalam pekerjaan dengan memperoleh pujian hasil kerja, penempatan, perlakuan, peralatan, dan 
suasana lingkungan kerja yang baik. Menurut Danang Sunyoto (2012:210) mengungkapkan kepuasan kerja (job satisfaction) adalah keadaan emosional yang menyenangkan atau tidak menyenangkan di mana para karyawan memandang pekerjaannya.

Siagian (2011:295) mengatakan bahwa kepuasan kerja merupakan suatu cara pandang seseorang baik yang bersifat positif maupun negatif tentang pekerjaannya. Menurut Osborn yang dikutip oleh Suwatno dan Priansa (2011:263) menjelaskan, "job satisfaction is the degree to which an individual feels positively or negatively about the various facets of the jobs tasks, the work setting and relationship with co-worker".

Colquitt, LePine, dan Wesson yang dikutip oleh Wibowo (2013:131) menjelaskan kepuasan kerja adalah tingkat perasaan menyenangkan yang diperoleh dari penilaian pekerjaan seseorang atau pengalaman kerja. George dan Jones (2012:71) menyatakan, "job satisfaction is the collection of feelings and beliefs that people have about their current jobs".

Noe, et.al (2012:458) mengungkapkan, "job satisfaction define as a pleasurable feeling that results from the perception that one's job fulfills or allow for the fulfillment of one's important job values". McShane dan Von Glinow (2010:108) menyatakan "Job satisfaction is a person's evaluation of his or her job and work context, is probably the most studied attitude in organizational behavior. It is an appraisal of the perceived job characteristics, work environment, and emotional experiences at work". Griffin dan Moorhead (2014:74) mengungkapkan bahwa, "job satisfaction reflects the extent to which people find gratification or fulfillment in their work".
Menurut Blum yang dikutip oleh Edy Sutrisno (2009:77) adalah: 1) Faktor individual, meliputi umur, kesehatan, watak, dan harapan. 2) Faktor sosial, meliputi hubungan kekeluargaan, pandangan pekerjaan, kebebasan berpolitik, dan hubungan kemasyarakatan. 3) Faktor utama dalam pekerjaan, meliputi upah, pengawasan, ketentraman kerja, kondisi kerja, dan kesempatan untuk maju. Selain itu, juga penghargaan terhadap kecakapan, hubungan sosial di dalam pekerjaan, ketepatan dalam menyelesaikan konflik antar manusia, perasaan diperlakukan adil baik yang menyangkut pribadi maupun tugas.

Gilmer yang juga dikutip Edy Sutrisno (2009:77-78), bahwa faktor-faktor yang mempengaruhi kepuasan kerja antara lain kesempatan untuk maju, keamanan kerja, gaji, perusahaan dan manajemen, pengawasan, faktor instrinsik dari pekerjaan, kondisi kerja, aspek sosial dalam pekerjaan, komunikasi, fasilitas.

Menurut Wexley dan Yuki (2005:160) menyatakan, kepuasan kerja dipengaruhi oleh beberapa aspek pekerja meliputi: upah/gaji, kondisi kerja, pengawasan, teman kerja, materi pekerjaan, jaminan kerja, serta kesempatan untuk maju. George dan Jones (2012:76-78), menjelaskan faktor-faktor yang mempengaruhi kepuasan kerja, yaitu : a) Personality, b) Values, c) The Work Situation, d) Social Influence.

Menurut Glison dan Durick yang dikutip oleh Panggabean (2004:129) mengemukakan bahwa faktor-faktor kepuasan kerja dapat dikelompokkan ke dalam tiga kelompok, yaitu: 1) Karakteristik pekerjaan terdiri atas keanekaragaman keterampilan (skill variety), identitas tugas (task identity), keberartian tugas (task significance), otonomi (autonomy), dan umpan balik pekerjaan (feedback). 2) Karakteristik organisasi 
mencakup skala usaha, kompleksitas, formalisasi, sentralisasi, jumlah anggota kelompok, lamanya beroperasi, usia kelompok kerja, dan kepemimpinan. 3) Karakteristik individu terdiri atas jenis kelamin, tingkat pendidikan, usia, masa kerja, status perkawinan, dan jumlah tanggungan.

Hasibuan (2005:203) mengungkapkan bahwa kepuasan kerja karyawan dipengaruhi oleh faktor-faktor sebagai berikut: 1) Balas jasa yang adil dan layak, 2) Penempatan yang tepat sesuai dengan keahlian, 3) Berat ringannya pekerjaan, 4) Suasana dan lingkungan pekerjaan, 5) Peralatan yang menunjang pelaksanaan pekerjaan, 6) Sikap pimpinan dalam kepemimpinannya, 7) Sifat pekerjaan monoton atau tidak.

Kreitner dan Kinicki yang dikutip oleh Panggabean (2004:129) mengemukakan bahwa aspek-aspek kepuasan kerja terdiri atas kepuasan terhadap pekerjaan, gaji, promosi, rekan kerja, dan penyelia. Menurut G. Terry yang dikutip oleh Suwatno dan Pariansa (2011:268) menyatakan, seorang pekerja cenderung bekerja dengan penuh semangat, bila kepuasan yang diperoleh tinggi dan pekerjaan tersebut sesuai dengan apa yang diinginkan pekerja. Ditinjau dari sudut pekerja ada empat aspek pokok yang dianggap penting yaitu: 1) Sifat umum pekerjaan, adanya tantangan dalam penggunaan kemampuan individu yang diperlukannya. 2) Kebebasan melaksanakan pekerjaan, kesempatan untuk menerapkan ide-ide pribadi, perasaan penting dalam hal melaksanakan pekerjaan dan membuat keputusan-keputusan penting tentang pekerjaan. 3) Kesempatan untuk tumbuh dan berkembang melalui latihan "feedback" tentang hasil pekerjaan dan menerima aneka macam tugas dalam jumlah yang layak. 4) Penghargaan tentang hasil pekerjaan yang diberikan atasan dengan cara yang terbuka, secara jujur dan pada waktu yang tepat.

Jex dan Britt (2008:120-121) menyatakan, "If employees perform OCB primarily because they are satisfied with their jobs, or feel that they have been treated fairly, organizations can influence the performance of $O C B$ by treating employees fairly and taking steps to enhance satisfaction". Pendapat Morrison's yang dikutip oleh Jex dan Britt (2008:120) menyatakan "was that employees were most likely to classify OCBs as in-role behaviors when they reported high levels of both job satisfaction and affective organizational commitment".

Robbins dan Judge (2013:84) menjelaskan bahwa "It seems logical to assume job satisfaction should be a major determinant of an employee's organizational citizenship behavior (OCB). Satisfied employees would seem more likely to talk positively about the organization, help others, and go beyond the normal expectations in their job, perhaps because they want to reciprocate their positive experiences. Consistent with this thinking, evidence suggests job satisfaction is moderately correlated with OCBs; people who are more satisfied with their jobs are more likely to engage in OCBs".

George dan Jones (2012:89) mengungkapkan "Affective commitment (like job satisfaction) may be more highly related to organizational citizenship behavior (OCB). Because these behaviors are voluntary, they tend to be more directly related to employees' attitudes toward an organization. When affective commitment is high, employees are likely to want to do what is good for the organization and, thus, perform OCBs".

\section{Metodologi Penelitian}


Penelitian ini bertujuan untuk memperoleh data empiris tentang: 1) Kepuasan kerja guru di SMK Negeri Kecamatan Pasar Minggu Kota Administrasi Jakarta Selatan. 2) Perilaku kewargaorganisasian (PKO) guru di SMK Negeri Kecamatan Pasar Minggu Kota Administrasi Jakarta Selatan. 3) Hubungan antara kepuasan kerja dengan PKO guru di SMK Negeri Kecamatan Pasar Minggu Kota Administrasi Jakarta Selatan.

Tempat yang dipilih untuk melaksanakan kegiatan penelitian adalah SMK Negeri yang berada di wilayah Kecamatan Pasar Minggu Kota Administrasi Jakarta Selatan. Waktu pelaksanaan penelitian ini yaitu dilaksanakan pada bulan Mei 2015 sampai dengan bulan Agustus 2015.

Metode penelitian yang digunakan dalam penelitian ini adalah metode penelitian survei untuk mengumpulkan data/informasi dari sebagian populasi yang dianggap dapat mewakili populasi tertentu. Jenis penelitian deskriptif yang digunakan adalah pendekatan korelasional. Penelitian ini menggunakan desain penelitian korelasi Product moment.

Populasi yang dipilih oleh peneliti yaitu guru Sekolah Menengah Kejuruan Negeri di Kecamatan Pasar Minggu Kota Administrasi Jakarta Selatan dengan jumlah 275 guru. Dalam penelitian ini peneliti menggunakan teknik simple random sampling. Dalam menentukan sampel penelitian, peneliti menggunakan rumus Slovin dengan tingkat kesalahan $10 \%$. Dengan demikian, sampel dalam penelitian ini adalah 73 orang guru SMK Negeri di Kecamatan Pasar Minggu Kota Administrasi Jakarta Selatan.

Dalam penelitian ini, teknik pengumpulan data yang digunakan yaitu kuesioner atau angket. Peneliti menggunakan skala Likert untuk pemberian nilai atau bobot pada setiap instrumen.
Kriteria yang digunakan untuk uji validitas butir adalah $r_{\text {tabel }}$ pada $\alpha=0.05$ dengan $n=20$, yaitu 0.444. Hasil dari uji coba instrumen Variabel X (Kepuasan Kerja) yang berjumlah 40 butir pernyataan diperoleh 33 butir pernyataan valid dan 7 butir pernyataan drop. Selanjutnya pada instrumen Variabel $Y$ (PKO) yang berjumlah 40 butir pernyataan diperoleh 35 butir pernyataan valid dan 5 butir pernyataan drop. Dengan kata lain pernyataan yang valid tersebut menandakan $r_{\text {hitung }}>r_{\text {tabel }}$.

Setelah uji validitas, selanjutnya adalah uji reliabilitas. Reliabilitas menunjuk pada satu pengertian bahwa sesuatu instrumen cukup dapat dipercaya untuk digunakan sebagai alat pengumpul data karena instrumen tersebut sudah baik. Pengujian dimaksudkan untuk menjamin instrumen yang digunakan merupakan sebuah instrumen yang handal, konsisten, dan stabil. Rumus yang digunakan untuk uji reliabilitas adalah rumus Alpha Cronbach.

Hasil perhitungan reliabilitas pada variabel $\mathrm{X}$ sebesar 0,943 dan variabel Y sebesar 0,951. Dengan jumlah responden uji coba sebanyak 20 guru dengan nilai $r_{\text {tabel }}=0.444$. Berdasarkan hasil perhitungan tersebut, maka angket kedua variabel dinyatakan reliabel untuk digunakan dalam penelitian.

Pada uji hipotesis dilakukan untuk mengetahui hasil dari hipotesis apakah ditolak atau diterima. Pengujian hipotesis ini dengan menggunakan korelasi product moment untuk memperoleh koefisien korelasi (r). Kemudian dilanjutkan dengan mencari koefisien determinasi (Kd). Lalu dibandingkan nilai t hitung tersebut dengan nilai $\mathrm{t}$ tabel dan dihasilkan pada $\mathrm{dk}=\mathrm{n}-2$ dengan taraf signifikansi $=0.05$, maka diperoleh hasil kriteria penerimaan dan penolakan hipotesis sebagai berikut: 
Jika thitung $>$ tabel maka Ho ditolak

Jika thitung $<\mathrm{t}_{\text {tabel }}$ maka Ho diterima

\section{Hasil Penelitian}

Sebelum melakukan pengujian prasyarat, deskripsi data penelitian dapat dijabarkan sebagai berikut:

\begin{tabular}{llll} 
& & \multicolumn{2}{c}{ Variabel } \\
& Data & $\mathbf{X}$ & $\mathbf{Y}$ \\
1 & Skor Minimal & 0.0015 & 0.0005 \\
2 & Skor Maksimal & 0.0826 & 0.0602 \\
3 & Skor Terendah & 94 & 79 \\
4 & Skor Tertinggi & 132 & 134 \\
5 & Total Skor & 8258 & 8319 \\
6 & Mean & 113.12 & 113.96 \\
7 & Modus & 123 & 114 \\
8 & Standar Deviasi & 9.24 & 11.50
\end{tabular}

Kemudian dilanjutkan dengan melakukan pengujian persyaratan analisis data, yang pertama adalah uji normalitas. Uji normalitas dilakukan untuk dapat mengetahui apakah sampel berasal dari populasi yang berdistirbusi normal atau tidak. Berdasarkan perhitungan normalitas dengan menggunakan Liliefors dengan $\alpha=0.05$ dan $\mathrm{n}=73$, maka dapat dideskripsikan sebagai berikut:

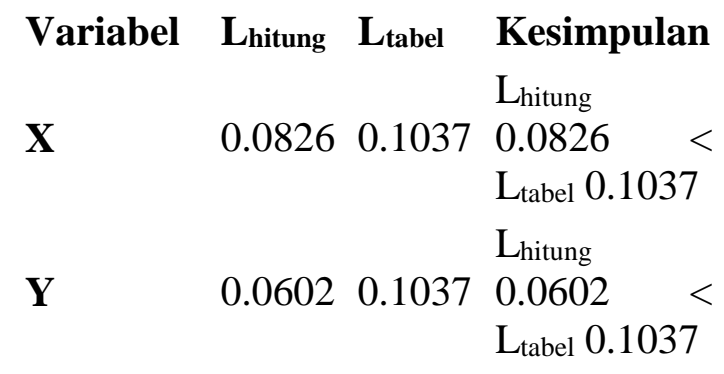

Berdasarkan dari deskripsi data perhitungan normalitas di atas, dapat disimpulkan bahwa data sampel Variabel X (Kepuasan Kerja) dan sampel Variabel Y (PKO) berasal dari populasi yang berdistribusi normal. Selanjutnya uji linieritas digunakan untuk mengetahui pengaruh variabel $X$ terhadap variabel $\mathrm{Y}$, yang akan ditarik suatu garis lurus pada diagram pencar.

Dari hasil uji regresi linier antara kedua variabel dalam penelitian ini didapat persamaan $\hat{Y}=50,17+0,56 x$. Bila digambarkan dalam bentuk grafik persamaan linier, maka tampak sebagai berikut:

Kemudian adalah mencari regresi linier yaitu menentukan ketetapan persamaan estimasi yang dihasilkan berdasarkan perhitungan dengan $\mathrm{dk}=\mathrm{n}-2=73-2=71$, diperoleh Standard Error of Estimate (Se) sebesar 10,3290. Selanjutnya dalam pengujian terhadap koefisien regresi dengan derajat kebebasan (degree of freedom) dan taraf signifikansi $\alpha=0,05$, maka nilai kritis pengujian adalah $t_{(n-k ; \alpha / 2)}=t_{(73-2 ; 0,05 / 2)}=$ $t_{(71 ; 0,025)}= \pm 2,290$. Dari hasil perhitungan yang dilakukan maka dapat diketahui kesalahan standar koefisien regresi $(\mathrm{Sb})$ adalah sebesar 0,1318. Dengan demikian nilai thitung yang dihasilkan adalah sebesar 4,280 .

Berdasarkan hasil hitungan di atas, menunjukkan nilai thitung berada di daerah penolakan $\mathrm{H}_{0}$, maka keputusannya adalah menolak $\mathrm{H}_{0}$, berarti nilai b secara statistik tidak sama dengan $0\left(\mathrm{H}_{0}: \beta \neq 0\right)$. Sehingga dapat disimpulkan secara statistik bahwa variabel $X$ yaitu kepuasan kerja berhubungan dengan variabel Y yaitu PKO.

Hipotesis yang dirumuskan dalam penelitian ini adalah hipotesis alternatif $\left(\mathrm{H}_{\mathrm{a}}\right)$ yang menyatakan bahwa terdapat hubungan positif antara kepuasan kerja dengan PKO guru di SMK Negeri Kecamatan Pasar Minggu Kota Administrasi Jakarta Selatan. Setelah data yang diperoleh, diolah dan dilakukan 
perhitungan dengan menggunakan rumus korelasi Product Moment, maka didapat koefisien korelasi $\left(\mathrm{r}_{\mathrm{xy}}\right)$ sebesar 0,45283, dan selanjutnya koefisien korelasi tersebut dimasukan ke dalam rumus uji $\mathrm{t}$ untuk pengujian hipotesis sehingga menghasilkan $t_{\text {hitung }}$ sebesar 4,280. Untuk uji satu pihak dengan $\mathrm{dk}=71$ serta taraf signifikansi $\alpha=$ 0,05 dari daftar signifikansi diperoleh $\mathrm{t}_{0,95}$ adalah sebesar 1,994. Dari hasil tersebut maka diperoleh $t_{\text {hitung }}$ lebih besar dari $t_{\text {tabel }}$ $\left(t_{\text {hitung }}=4,280>t_{\text {tabel }}=1,994\right)$, sehingga $\mathrm{H}_{0}$ dinyatakan dalam koefisien korelasi signifikan ditolak. Dapat disimpulkan bahwa terdapat hubungan yang positif antara kepuasan kerja dengan PKO guru di SMK Negeri Kecamatan Pasar Minggu Kota Administrasi Jakarta Selatan.

Koefisien determinasi (Kd) antara kedua variabel adalah 20,51\%. Hal ini menunjukkan bahwa besarnya kontribusi yang diberikan kepuasan kerja terhadap PKO guru di SMK Negeri Kecamatan Pasar Minggu Kota Administrasi Jakarta Selatan adalah sebesar 20,51\%. Sedangkan 79,49\% lainnya dipengaruhi oleh variabel-variabel lain.

\section{Pembahasan}

Dengan demikian hasil penelitian ini menyatakan kebenaran adanya hubungan antara kepuasan kerja dengan PKO guru, sesuai dengan teori yang dijelaskan para ahli. Jex dan Britt (2008:120-121) menyatakan, "If employees perform OCB primarily because they are satisfied with their jobs, or feel that they have been treated fairly, organizations can influence the performance of $O C B$ by treating employees fairly and taking steps to enhance satisfaction”. Selanjutnya, Morrison's yang dikutip oleh Jex dan Britt (2008:120) menyatakan "was that employees were most likely to classify OCBs as in-role behaviors when they reported high levels of both job satisfaction and affective organizational commitment".

Sementara itu, teori yang hampir serupa juga diungkapkan Robbins dan Judge (2013:84) yang menjelaskan bahwa "It seems logical to assume job satisfaction should be a major determinant of an employee's organizational citizenship behavior (OCB). Satisfied employees would seem more likely to talk positively about the organization, help others, and go beyond the normal expectations in their job, perhaps because they want to reciprocate their positive experiences. Consistent with this thinking, evidence suggests job satisfaction is moderately correlated with OCBs; people who are more satisfied with their jobs are more likely to engage in OCBs".

Pendapat lain juga diungkapkan George dan Jones (2012:89) yaitu "Affective commitment (like job satisfaction) may be more highly related to organizational citizenship behavior (OCB). Because these behaviors are voluntary, they tend to be more directly related to employees' attitudes toward an organization. When affective commitment is high, employees are likely to want to do what is good for the organization and, thus, perform OCBs".

\section{Kesimpulan}

1. Terdapat hubungan yang positif antara kepuasan kerja dengan PKO guru di SMK Negeri Kecamatan Pasar Minggu Kota Administrasi Jakarta Selatan. Adapun kontribusi yang diberikan oleh kepuasan kerja terhadap PKO guru adalah sebesar 20,51\%. Dari angka konstribusi tersebut dapat disimpulkan bahwa terdapat faktor-faktor lainnya yang dapat mempengaruhi PKO guru selain faktor kepuasan kerja. 
2. Kepuasan kerja guru dapat ditunjukkan melalui sikap guru dalam bekerja yaitu melakukan kegiatan belajar mengajar. Guru yang merasakan kepuasan akan bekerja dengan baik yaitu dengan melaksanakan kegiatan belajar mengajar di sekolah dengan baik. Tetapi apabila guru kurang merasakan kepuasan dalam bekerja maka guru akan mengajar sesuai dengan kehendaknya sendiri.

3. Kepuasan kerja dapat dikatakan mempunyai pengaruh terhadap timbulnya PKO guru. Guru yang senantiasa merasakan kepuasan terhadap pekerjaannya akan membuat guru menyukai organisasinya yaitu sekolah. Guru yang menyukai sekolah akan menimbulkan perasaan bahwa guru adalah bagian dari sekolah, sehingga guru mau melakukan hal lebih untuk sekolah walaupun itu diluar dari deskripsi tugasnya. Hal ini pada akhirnya akan menimbulkan PKO dalam melakukan pekerjaan, yang mana PKO merupakan perilaku ekstra guru yang melebihi deskripsi tugas formalnya yang menjadi tanggung jawabnya dan dilakukan secara sukarela tanpa adanya paksaan, dengan tujuan membantu rekan kerja atau demi kelancaran tercapainya tujuan sekolah.

\section{Saran}

1. Kepada Kepala sekolah, saran yang dapat diberikan adalah selaku pimpinan di sekolah, hendaknya memperhatikan kepuasan kerja yang dirasakan oleh setiap guru. Diusahakan agar mampu memberikan kepuasan kerja dan apabila terdapat ketidakpuasan kerja agar mau mendengarkan keluhan yang dirasakan oleh guru-guru.

2. Kepada guru-guru di sekolah, saran yang dapat diberikan adalah hendaknya terus berupaya meningkatkan kinerja dan selalu menampilkan PKO yang tinggi di dalam lingkungan sekolah agar tercapainya tujuan sekolah sesuai dengan apa yang diharapkan.

3. Kepada peneliti lain, saran yang dapat diberikan adalah jika ingin meneliti tentang hal ini diharapkan dapat meneliti lebih luas, lebih mengembangkan, dan menyempurnakan penelitian ini sehingga dapat memberi manfaat dan pengaruh yang lebih baik pula bagi perkembangan dunia pendidikan di Indonesia.

\section{Daftar Pustaka}

Arikunto, Suharsimi. (2010). Prosedur Penelitian Suatu Pendekatan Praktik. Jakarta: PT Rineka Cipta.

George, Jennifer M. dan Gareth R. Jones. (2008). Understanding and Managing Organizational Behavior. New Jersey: Pearson Education.

George, Jennifer M. dan Gareth R. Jones. (2012). Understanding and Managing Organizational Behavior. New Jersey: Pearson Education.

Griffin, Ricky W. dan Gregory Moorhead. (2014). Organizational Behavior Managing people and Organizations. Mason: SouthWestern.

Hasibuan, Malayu S.P. (2005). Manajemen Sumber Daya Manusia. Jakarta: Bumi

Aksara. 
Hellriegel, Don dan John W. Slocum. (2011). Organizational Behavior. Mason: South-Western.

Jex, Steve M. (2002). Organizational Psychology: A Scientist-Practitioner Approach. New York: John Wiley \& Sons.

Jex, Steve M. dan Thomas W. Britt. (2008). Organizational Psychology (A ScientistPractitioner Approach). New Jersey: John Wiley \& Sons.

Kreitner, Robert dan Angelo Kinicki. (2008). Organizational Behavior. New York: McGraw-Hill.

Locke, Edwin A. (2009). Handbook of Principles of Organizational Behavior. West Sussex: John Wiley \& Sons.

Luthans, Fred. (2011). Organizational Behavior. New York: The Mc-Graw-Hill.

McShane, Steven L. dan Mary Ann Von Glinow. (2010). Organizational Behavior: Emerging Knowledge and Practice for the Real Word. New York: McGraw-Hill.

Noe, Raymond A. et.al. (2012). Human Resource Management: Gaining A Competitive Advantage. New York: McGraw-Hill.

Panggabean, Mutiara Sibarani. (2004). Manajemen Sumber Daya Manusia. Bogor: Ghalia Indonesia.

Robbins, Stephen P. dan Mary Coutler. (2007). Management. New Jersey: Pearson Education.
Robbins, Stephen P. dan Timothi A. Judge. (2013). Organizational Behavior. New Jersey: Pearson Education.

Sarwono, Jonathan. (2006). Metode Penelitian Kuantitatif dan Kualitatif. Yogyakarta : Graha Ilmu.

Schermerhorn, John R. et.al. (2010). Organizational Behavior. New Jersey: John Wiley \& Sons. Inc.

Siagian, Sondang P. (2011). Manajemen Sumber Daya Manusia. Jakarta: Bumi Aksara.

Suwatno dan Donni Juni Pariansa. (2011). Manajemen SDM dalam Organisasi Publik dan Bisnis. Bandung: Alfabeta.

Sudjana. (2005). Metoda Statistika. Bandung: Tarsito.

Sugiyono. (2013). Metode Penelitian Manajemen. Bandung : Alfabeta.

Sunyoto, Danang. (2012). Manajemen Sumber Daya Manusia. Yogyakarta: CAPS.

Sutrisno, Edy. (2009). Manajemen Sumber Daya Manusia. Jakarta: Kencana.

Wexley, Kenneth N. dan Gary A. Yuki. (2005). Perilaku Organisasi dan Psikologi Personalia. Jakarta: Rineka Cipta.

Wibowo. (2013). Perilaku dalam Organisasi. Jakarta: Rajawali Pers.

Hendry. (2013). Organizational Citizenship Behavior (OCB). Diakses pada tanggal 25 Maret 2015 pukul 22.30 WIB. http://teorionline.net/organizationalcitizenship-behavior-ocb/ 